\title{
Study of Temperature Field and Structure Optimization for Runways in Permafrost Regions
}

\author{
Xiaolan Liu ${ }^{1, *}$, Yixiang Chen ${ }^{2}$, Yan Zhou ${ }^{1}$, Kai Zhang ${ }^{3}$ \\ ${ }^{1}$ Tianjin Key Laboratory of Civil Structure Protection and Reinforcement, Tianjin Chengjian University, Tianjin, 300384, China \\ ${ }^{2}$ Civil Engineering College, Tianjin Chengjian University, Tianjin, 300384, China \\ ${ }^{3}$ Tianjin Municipal Engineering Design \& Research Institute Co., Ltd., Tianjin, 300051, China \\ ${ }^{*}$ Corresponding Author: Xiaolan Liu. Email: d1066323835@163.com
}

Received: 27 June 2021 Accepted: 19 August 2021

\begin{abstract}
Pavement construction in permafrost regions is complicated by the fact that the permafrost properties are influenced by the temperature and are extremely unstable. The numerical model for runway structures in permafrost regions is applied to analyze the time-space characteristics of the temperature field and the depth of the frozen layer. The influence of the installation layer is studied to enable structural optimization of the runway. Numerical results show that the temperature stabilization depth, low- and high-temperature interlayer response ranges, and maximum depth of the frozen layer are greater in runway engineering than in highway and railway engineering. The time history curves for the pavement and natural surface are similar, and the development of freezing and thawing is approximately linear. The pavement and natural surface have similar thawing rates, but the freezing rate of the natural surface is faster than that of the pavement. The depth of the frozen layer and the time of the frozen are greater for the natural surface than for the pavement. The installation layer helps to stabilize the temperature of the subgrade and reduces the freezing and thawing rates. This study provides technical support for the design and maintenance of runways in permafrost regions.
\end{abstract}

\section{KEYWORDS}

Temperature; the depth of the frozen layer; structure optimization; runway; permafrost

\section{Introduction}

Permafrost is an anisotropic and inhomogeneous complex structure composed of gas, water, ice, and soil [1,2]. It is sensitive to temperature, and has poor thermal stability [3,4]. Moreover, ice-water phase changes often appear in permafrost regions, leading to thawing settlement and frost heave in transportation infrastructure [5,6]. Therefore, the temperature field of transportation infrastructure in permafrost regions has been widely studied. Harlan [7] built a moisture migration model based on the water movement characteristics of unsaturated frozen soil, and incorporated the heat capacity into the heat transfer equation to establish a water-heat coupling transmission model. This water-heat coupling transmission model did not, however, include the stress field caused by changes in the temperature field and moisture field. Dempsey [8] and Noorishad

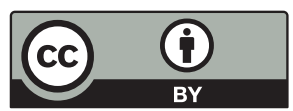

This work is licensed under a Creative Commons Attribution 4.0 International License, which permits unrestricted use, distribution, and reproduction in any medium, provided the original work is properly cited. 
et al. [9] proposed a water-heat-force coupling model for unsaturated frozen soil, providing the theoretical basis for temperature field research in permafrost regions. Mu et al. [10] then established a water-heat-force coupling model for saturated frozen soil. Masters et al. [11] analyzed the temperature field of permafrost regions based on the pore pressure and temperature, while Fortier et al. [12] considered the influence of snow in the water-heat-force coupling model and compared the temperature fields of the shoulder and subgrade in highway engineering. Sergei et al. [13] used the water-heat-force coupling model to analyze the subgrade temperature field of Russian railways, and Chen et al. [14-16] later studied the effect of gravel size, gravel thickness, and boundary on the temperature field of railway subgrade. Recently, Liu et al. [17] conducted a study of the temperature field of separated subgrade.

To understand the actual situation of transportation infrastructure, a large number of experiments have been conducted. He et al. [18-22] explored the influence of the ballast layer, gravel size and thickness, boundary, and other factors on the temperature field of frozen soils based on laboratory experiments. Harris et al. [23-28] used data measured during field tests to analyze the effects of the gravel layer, ventilation pipes, and insulation layer on the temperature field of natural foundations and highway subgrade. Niu et al. [29-33] discussed the influence of the gravel layer, ventilation pipes, insulation layer, thermal pipes, and sun shielding on the temperature of railway subgrade. In the 1960s, France, Greenland, USA, China, Norway, Canada, Russia, and Ireland built a large number of airport runways in permafrost regions. The main types include bedrock runways, filling gravel runways, installation layer runways, and thermal-pipe runways [34-36]. Such runways have high topographical and geological requirements, involve the excavation of large soil volumes at significant cost, and are difficult to replace and maintain.

Existing research on transport infrastructure in permafrost regions has tended to focus on highway and railway engineering. However, runways are wider, have a larger absorption area, and involve greater disturbance to permafrost regions than highways and railways. Furthermore, existing airport runway construction experience is helpful for small airports, but is difficult to apply more widely to larger airports. Hence, this study has established and verified a temperature model for large airports. The temperature of the natural surface and pavement was compared at different depths to analyze the steady process of subgrade temperature. Additionally, the depth of the frozen layer of the natural surface and pavement was compared at different times to study the thawing rate of permafrost runways. Optimization measures for runway structures in permafrost regions are proposed based on the changes and distribution of subgrade temperature. The research findings provide the valuable information for the design, construction, operation, maintenance, safety, and management of airport engineering in the frozen soil regions, especially for the frozen silty clay regions.

\section{Hydrothermal Coupling Theory}

\subsection{Governing Equations}

The heat balance control equations of a three-dimensional transient temperature field are established based on the following practical assumptions: (1) the pavement structure layers, natural surface, and subgrade are uniform and isotropic; (2) the boundary of each structure layer does not permit moisture migration; (3) the pavement structure layers, natural surface, and subgrade obey the energy conservation law and only include heat transfer effects [22,31]. Under these assumptions, we can write. 
$\rho C \frac{\partial T}{\partial t}=\frac{\partial}{\partial x}\left(\lambda \frac{\partial T}{\partial x}\right)+\frac{\partial}{\partial y}\left(\lambda \frac{\partial T}{\partial y}\right)+\frac{\partial}{\partial z}\left(\lambda \frac{\partial T}{\partial z}\right)$

Here, $T$ is the temperature, $t$ is the time, $\lambda$ is the thermal conductivity, $\rho$ is the density, $C$ is the heat capacity, and $x, y, z$ are the rectangular coordinates.

Based on the method of sensible heat capacity, it is assumed that a phase change occurs in a certain temperature range. $\lambda$ and $C$ can be obtained by Eqs. (2) and (3) [22].

$$
\begin{aligned}
& \lambda= \begin{cases}\lambda_{f} & T<T_{m}-\Delta T \\
\lambda_{f}+\frac{\lambda_{u}-\lambda_{f}}{2 \Delta T} & T_{m}-\Delta T \leq T \leq T_{m}+\Delta T \\
\lambda_{u} & T>T_{m}+\Delta T\end{cases} \\
& C= \begin{cases}C_{f} & T<T_{m}-\Delta T \\
\frac{L}{2 \Delta T}+\frac{C_{f}+C_{u}}{2} & T_{m}-\Delta T<T<T_{m}+\Delta T \\
C_{u} & T>T_{m}+\Delta T\end{cases}
\end{aligned}
$$

Here, $L$ is the latent heat per unit volume media, $\lambda_{f}$ is the thermal conductivity of frozen soil, $C_{f}$ is the heat capacity of frozen soil, $\lambda_{u}$ is the thermal conductivity of unfrozen soil, $C_{u}$ is the heat capacity of unfrozen soil, $T_{m}$ is the temperature of the phase change, and $\Delta T$ is the variation amplitude of temperature.

\subsection{Boundary Conditions}

There are three kinds of boundary conditions for the temperature field based on heatconduction theories. The first boundary condition is established based on the surface temperature of the permafrost region, and is applied at the surface in numerical models. This boundary condition is written as [16]

$T=T_{0}+\Delta T+a \sin \left(\frac{2 \pi t}{8760}+b\right)+\frac{\alpha t}{8760 \times 30}$

Here, $T_{0}$ is the mean annual ground temperature of the boundary layer, taken as the mean annual air temperature. $\Delta T$ is the temperature increment of the boundary layer, and can be set to $2.5^{\circ} \mathrm{C}$ for natural surfaces and $4.5^{\circ} \mathrm{C}$ for pavement; $a$ is the temperature variation amplitude, which is $12^{\circ} \mathrm{C}$ for natural surfaces and $15^{\circ} \mathrm{C}$ for pavement; $t$ is the time in hours; $b$ is the initial phase, which is equal to 0 at the initial time of April 01 in the northeast of China; and $\alpha$ is the temperature increment of global climate warming over the next 30 years, taken to be $1.5^{\circ} \mathrm{C}$ [22].

The second kind of boundary condition is an adiabatic boundary condition, and is applied on both sides of numerical models. This condition is written as [22]

$\frac{\partial T}{\partial n}=0$

Here, $\partial T / \partial n$ is the temperature gradient.

The third kind of boundary condition is a constant temperature gradient of $0.03{ }^{\circ} \mathrm{C} / \mathrm{m}$. This is applied at the bottom of numerical models, and is written as [22]

$\frac{\partial T}{\partial n}=0.03$ 


\section{Numerical Simulations}

\subsection{Numerical Model}

As shown in Fig. 1, the results of an engineering geological survey indicate that the natural surface consists of $0.4 \mathrm{~m}$ of clay soil, $1.6 \mathrm{~m}$ of silty clay soil, and $18 \mathrm{~m}$ of strongly weathered rock [20]. According to the specifications for the asphalt pavement design of civil airports [37], the pavement structure consists of an upper surface, under surface, upper base layer, under base layer, and subbase layer. To eliminate the boundary effect, a $40 \mathrm{~m}$ wide natural surface should be placed on both sides of the pavement structures. The numerical model of the pavement structure is $45 \mathrm{~m}$ wide and $15 \mathrm{~m}$ long.

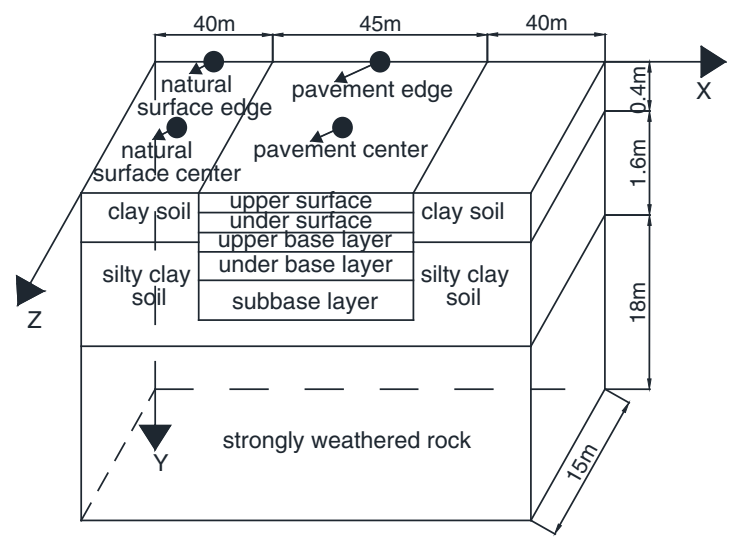

Figure 1: Schematic diagram of numerical model

The calculation time is 10 years. The boundary condition of the numerical model is determined by Eqs. (4)-(6). The initial temperature field is taken as $-1{ }^{\circ} \mathrm{C}$ [38]. An apparent heat capacity method is used to simulate the phase change that occurs in a certain temperature range. The thermal parameters of the natural surface and pavement structure are listed in Tables 1 and 2 [20].

Table 1: Thermal parameters of natural surface

\begin{tabular}{llllllllll}
\hline Thermal parameters & & $-20^{\circ} \mathrm{C}$ & $-10^{\circ} \mathrm{C}$ & $-5^{\circ} \mathrm{C}$ & $-2^{\circ} \mathrm{C}$ & $-1{ }^{\circ} \mathrm{C}$ & $-0.5^{\circ} \mathrm{C}$ & $0^{\circ} \mathrm{C}$ & $20^{\circ} \mathrm{C}$ \\
\hline Clay soil & $\rho /\left(\mathrm{kg} / \mathrm{m}^{3}\right)$ & 1870 & 1870 & 1870 & 1870 & 1870 & 1870 & 1870 & 1870 \\
& $\lambda /\left(\mathrm{W} /\left(\mathrm{m}^{\circ} \mathrm{C}\right)\right)$ & 2.4 & 2.4 & 2.4 & 2.4 & 2.4 & 2.4 & 1.54 & 1.54 \\
& $c /\left(\mathrm{J} /\left(\mathrm{kg}^{\circ} \mathrm{C}\right)\right)$ & 835 & 840 & 850 & 860 & 870 & 900 & 1070 & 1070 \\
Silty clay soil & $\rho /\left(\mathrm{kg} / \mathrm{m}^{3}\right)$ & 1950 & 1950 & 1950 & 1950 & 1950 & 1950 & 1950 & 1950 \\
& $\lambda /\left(\mathrm{W} /\left(\mathrm{m}^{\circ} \mathrm{C}\right)\right)$ & 1.81 & 1.81 & 1.81 & 1.81 & 1.81 & 1.81 & 1.5 & 1.5 \\
& $c /\left(\mathrm{J} /\left(\mathrm{kg}^{\circ} \mathrm{C}\right)\right)$ & 970 & 1050 & 1090 & 1115 & 1140 & 1210 & 1285 & 1285 \\
Strongly weathered rock & $\rho /\left(\mathrm{kg} / \mathrm{m}^{3}\right)$ & 2150 & 2150 & 2150 & 2150 & 2150 & 2150 & 2150 & 2150 \\
& $\lambda /\left(\mathrm{W} /\left(\mathrm{m}^{\circ} \mathrm{C}\right)\right)$ & 2.5 & 2.5 & 2.5 & 2.5 & 2.5 & 2.5 & 2.01 & 2.01 \\
& $c /\left(\mathrm{J} /\left(\mathrm{kg}^{\circ} \mathrm{C}\right)\right)$ & 950 & 1060 & 1110 & 1140 & 1190 & 1250 & 1350 & 1350 \\
\hline
\end{tabular}


Table 2: Thermal parameters of pavement structure

\begin{tabular}{llllll}
\hline Pavement structure & Material & $\rho /\left(\mathrm{kg} / \mathrm{m}^{3}\right)$ & Thickness $/(\mathrm{m})$ & $c /\left(\mathrm{J} /\left(\mathrm{kg}{ }^{\circ} \mathrm{C}\right)\right)$ & $\lambda /\left(\mathrm{W} /\left(\mathrm{m}{ }^{\circ} \mathrm{C}\right)\right)$ \\
\hline Upper surface & Asphalt concrete & 2300 & 0.15 & 1670 & 1.15 \\
Under surface & Asphalt concrete & 2320 & 0.15 & 1670 & 1.20 \\
Upper base layer & $\begin{array}{l}\text { Cement stabilized } \\
\text { macadam }\end{array}$ & 2200 & 0.3 & 960 & 1.56 \\
Under base layer & $\begin{array}{l}\text { Cement stabilized } \\
\text { macadam }\end{array}$ & 2233 & 0.35 & 920 & 2.04 \\
Subbase layer & Graded macadam & 2000 & 0.5 & 1100 & 1.68 \\
\hline
\end{tabular}

\subsection{Verification of Numerical Model}

Due to the lack of runway monitoring data, the reliability of the numerical model is verified through a comparison with the temperature field characteristics and the depth of the frozen layer of previous models. Transient thermal analysis of the runway is conducted over a period of 10 years based on the initial temperature field. The temperature field after 10 years of operation in the Northeast of China is shown in Fig. 2. The change in the depth of the frozen layer with respect to time after 10 years of operation in the Northeast of China is shown in Fig. 3.

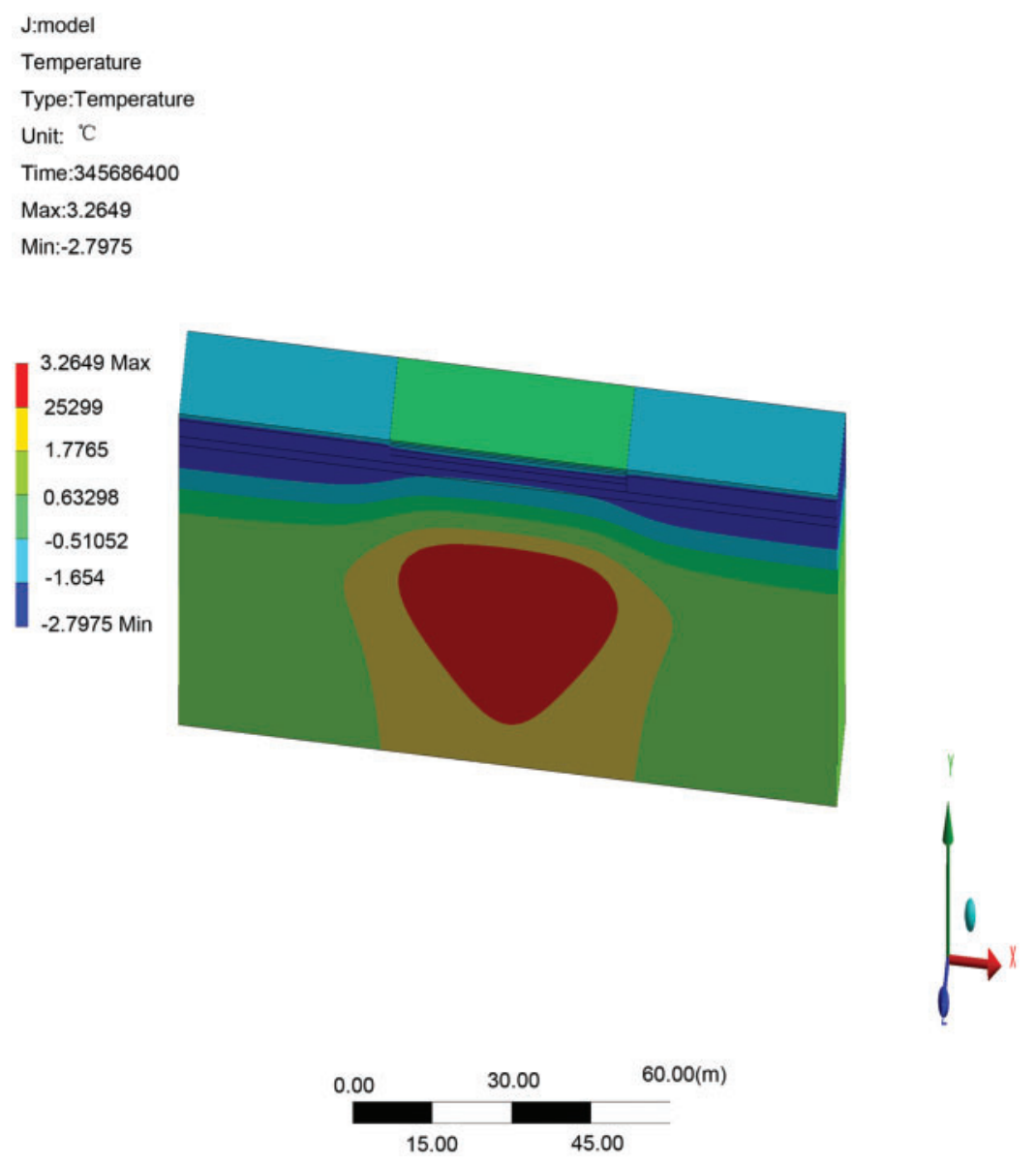

Figure 2: Temperature field after 10 years of operation in the Northeast of China 


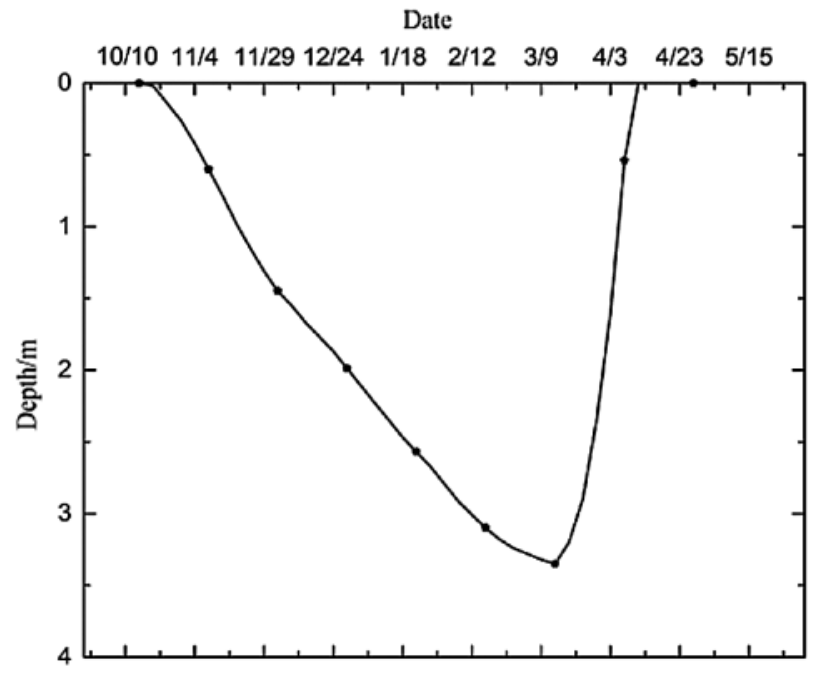

(a)

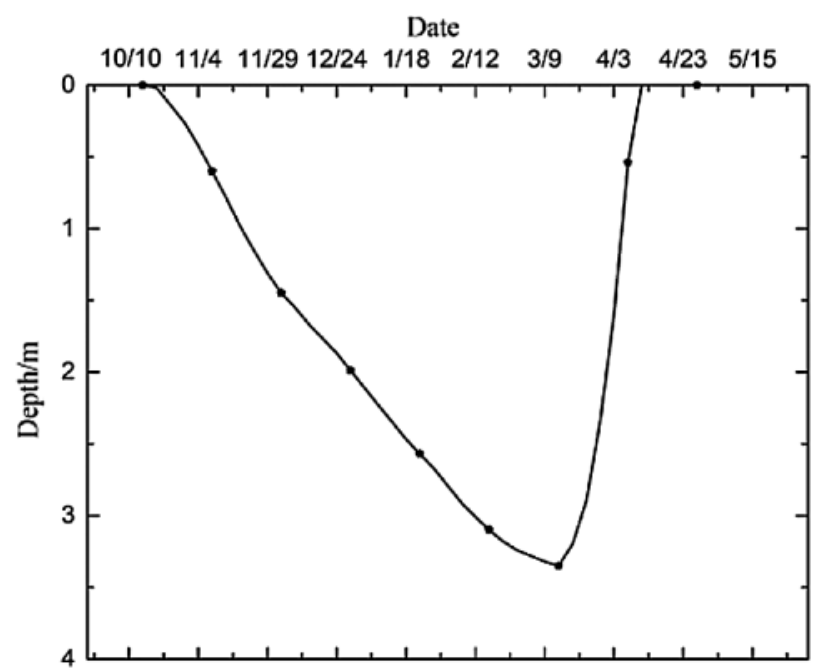

(b)

Figure 3: The depth of the frozen layer with respect to time after 10 years of operation at (a) pavement center and (b) pavement edge

Fig. 2 shows that the maximum depth of the frozen layer of the pavement generally appears on the 346th day after the air temperature reaches the maximum value, which is at the end of March in the second year. The results in Fig. 2 are in accord with those of [28] and [39]. Fig. 3 shows that the pavement begins to freeze in the middle of October, reaches the maximum depth of the frozen layer at the end of March, starts to thaw at the beginning of April, and has completely thawed by the end of April. The characteristics of the pavement freezing and thawing are consistent with those reported by Wang et al. [40] and Li [20]. However, the maximum depth of the frozen layer of the pavement in runway engineering is about $3.35 \mathrm{~m}$, somewhat deeper than in highway and railway engineering. The maximum depth of the frozen layer of the pavement is consistent with that found by $\mathrm{Li} \mathrm{[20]} \mathrm{and} \mathrm{Duan} \mathrm{[38].} \mathrm{Therefore,} \mathrm{the} \mathrm{parameters} \mathrm{and} \mathrm{boundary}$ conditions of the runway structure model are reasonable, and the numerical model of the runway structure can be applied to analyze the temperature and the depth of the frozen layer response of permafrost runways.

\section{Results and Discussion}

\subsection{Stability of Temperature Field}

Generally, the pavement contains more heat than natural surfaces, which changes the original thermal balance of the ground temperature. The pavement transfers heat to the natural surface and subgrade until the new thermal dynamic equilibrium is reached. Therefore, the change in temperature with respect to time, as shown in Fig. 4, can be used to analyze the stability of the temperature field in runway engineering.

Fig. 4 indicates that the heat dissipation processes of the pavement and natural surface continue for 5 or 6 years until the new thermal dynamic equilibrium is reached. The temperature of the pavement and natural surface then exhibit a stable and cyclical variation. As the depth increases, the temperature amplitudes of the pavement and natural surface gradually decrease with some phase delay. This phenomenon occurs because much of the heat in the pavement does not 
dissipate quickly, and requires a long time to gradually dissipate. Moreover, the temperature gradually decreases as the heat conduction depth increases. Finally, the pavement and natural surface reach a new thermal dynamic equilibrium. In addition, the temperature of the pavement and natural surface presents a slightly rising phenomenon due to the impact of global climate warming.

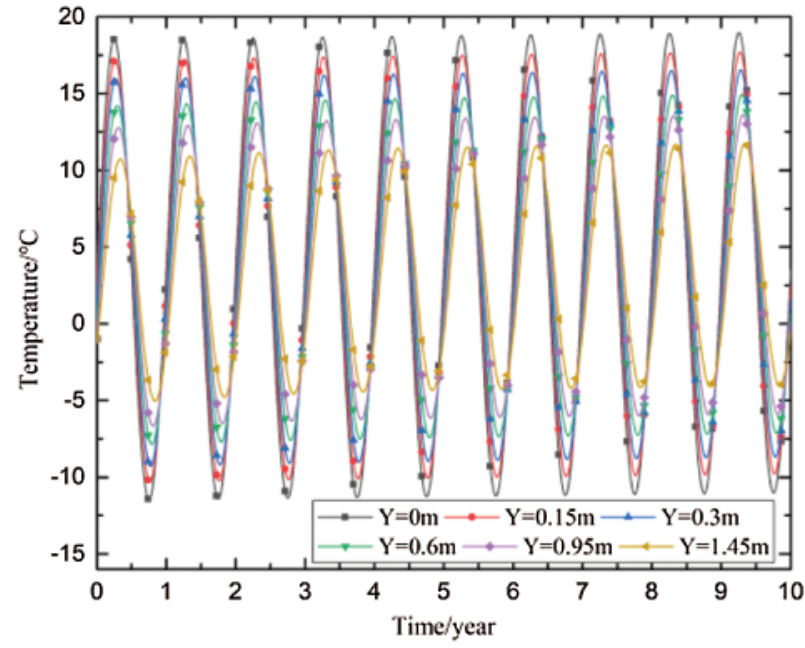

(a)

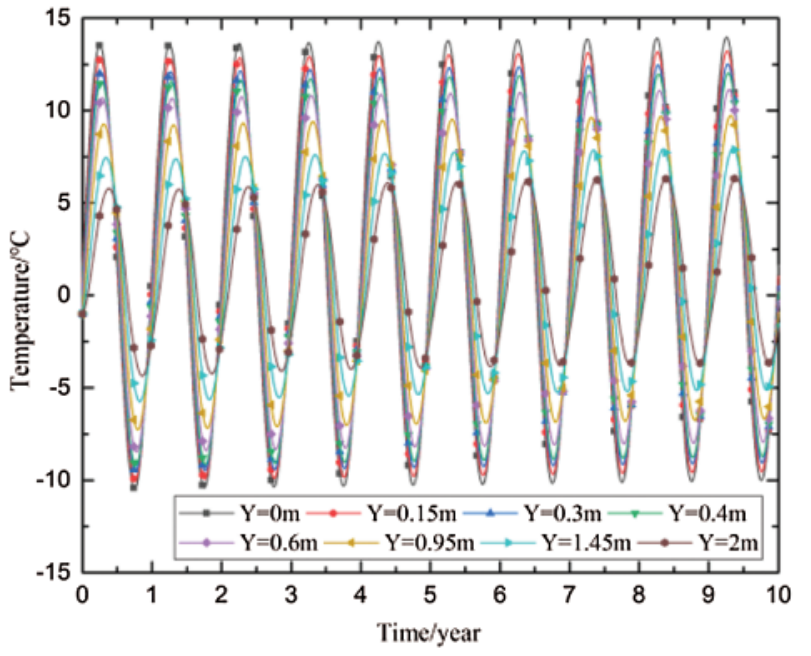

(c)

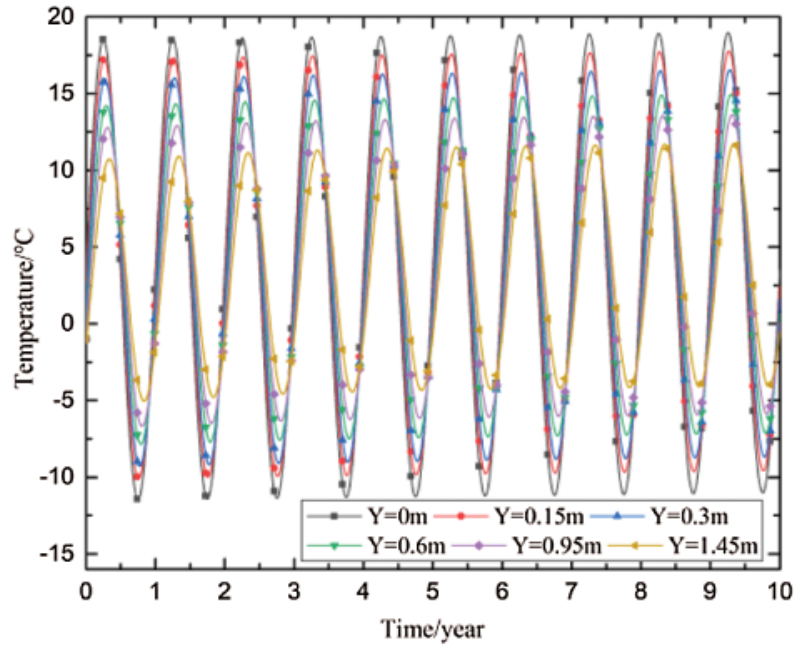

(b)

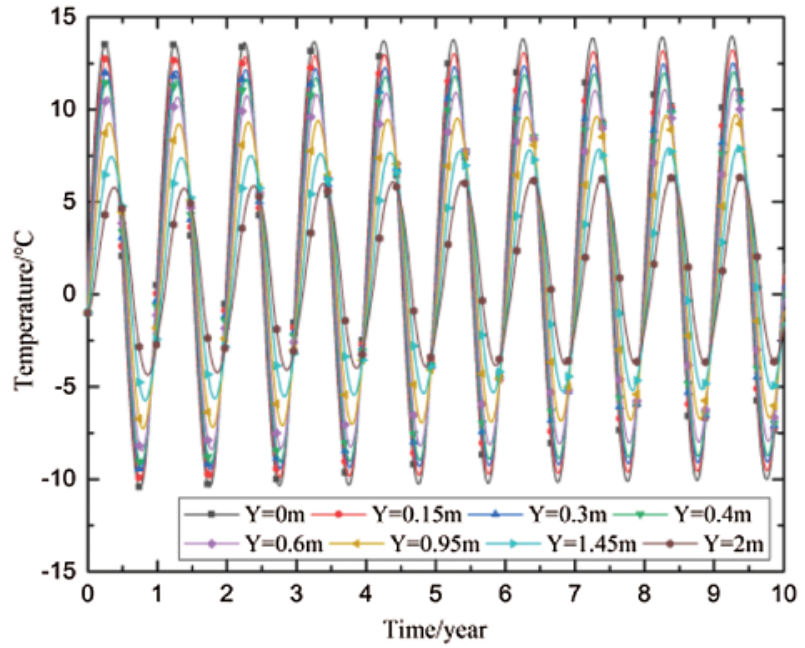

(d)

Figure 4: Temperature with respect to time at (a) pavement center, (b) pavement edge, (c) natural surface center, and (d) natural surface edge

Figs. $4 \mathrm{a}$ and $4 \mathrm{~b}$ show that the change in temperature with respect to time is almost identical at the pavement center and the pavement edge. Figs. $4 \mathrm{c}$ and $4 \mathrm{~d}$ show that the natural surface center and edge also exhibit similar changes in temperature over time. This is because the pavement structure layers, natural surface, and subgrade are assumed to be uniform and isotropic. Hence, the temperatures of the pavement center and the natural surface center are adopted to study the temperature characteristics at different depths. Figs. $4 \mathrm{a}$ and $4 \mathrm{c}$ indicate that the temperature of the pavement is higher than that of the natural surface at the same depth and time. The difference 
in the highest temperature of the pavement and the natural surface is about $3.5^{\circ} \mathrm{C}$, whereas the difference in the lowest temperature is about $1{ }^{\circ} \mathrm{C}$. The phase delay in the runway is greater than that in highways and railways. The reason is that the solar absorption coefficient of the pavement is greater than that of the natural surface, and the quantity of heat absorbed by the pavement is greater than that absorbed by the natural surface. Furthermore, the runway is wider than a highway or a railway, so the heat absorption area is larger. Hence, the quantity of heat absorbed by the runway is greater than that absorbed by a highway or railway, and so a longer time is required for heat dissipation.

\subsection{Temperature Characteristics at Different Depths}

The stability of the temperature field shows that the temperature variation amplitude decreases as the depth increases. To study the relationship between temperature and depth, the temperaturedepth curves on the 15th day of each month after 10 years of operation are shown in Fig. 5.

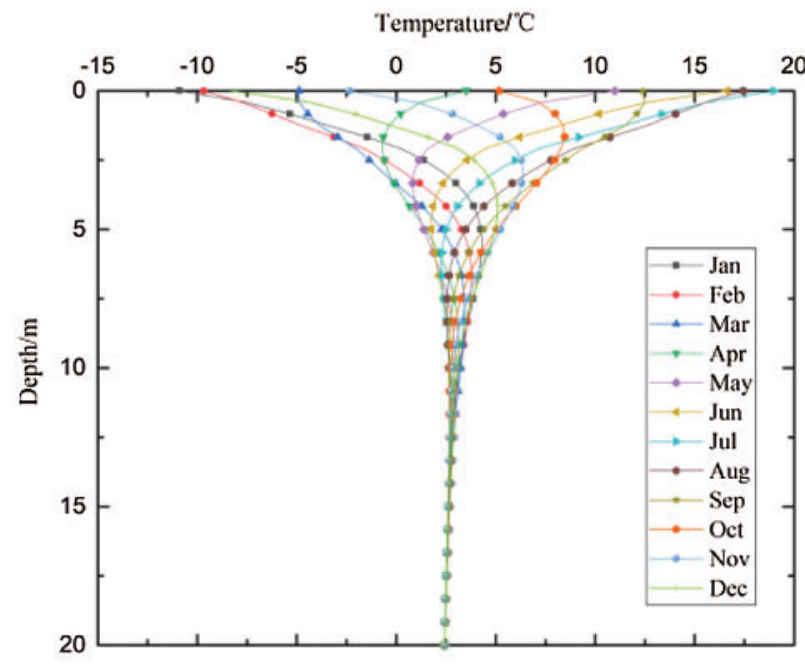

(a)

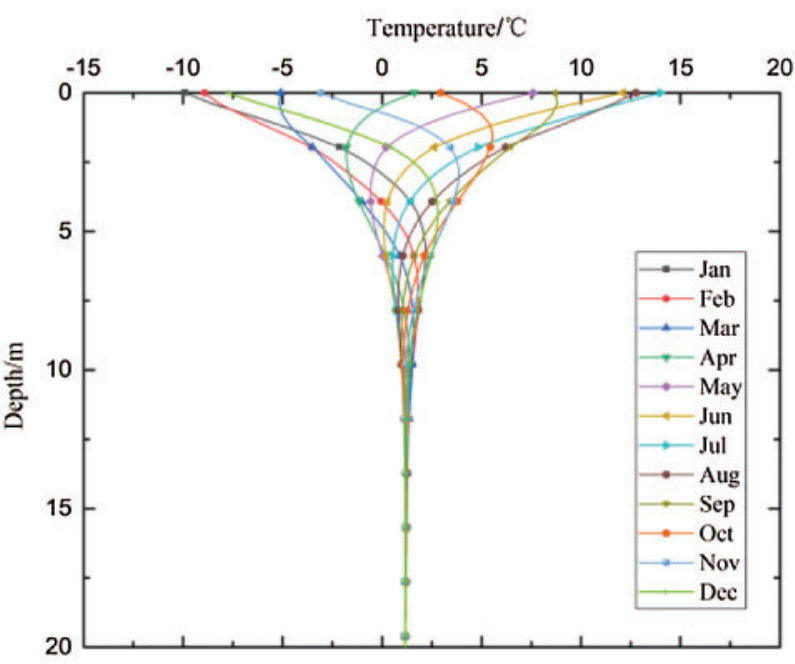

(b)

Figure 5: Temperature-depth curves at (a) pavement center and (b) natural surface center

Fig. 5 indicates that the temperature envelopes of the pavement and natural surface are funnel-shaped over the whole year. The temperature ranges of the pavement and natural surface decrease at increased depths, and tend to a constant temperature. The upper temperature-depth curves of the pavement and natural surface that shift to the left indicate that low-temperature interlayers exist in the pavement structure and natural surface. Similarly, the upper temperaturedepth curves that are shifted to the right mean that high-temperature interlayers exist in the pavement structure and natural surface. These temperature characteristics are similar to those observed in highway and railway engineering [28,39]. However, the low- and high-temperature interlayers in runway engineering are thicker than those found in highway and railway engineering. The response depth of the runway, i.e., the depth at which the temperature envelopes of the pavement and natural surface reach a stable value, is greater than that of highways and railways. The reason is that the wide pavement in runway engineering absorbs more heat and is more harmful to heat dissipation than highways and railways, which increases the depth range of the temperature response. 
In Fig. 5a, because January is the coldest month with the least solar radiation, the temperature of the pavement center goes from low to high and back to low as the depth increases. The top of the pavement is significantly affected by the external environment and begins to cool down first. The temperature variation of the pavement decreases as the depth increases, and is barely influenced by the external environment at depths of more than $12 \mathrm{~m}$. The air temperature increases from January to April. In April, the temperature of the pavement center exhibits highlow-high-low characteristics as the depth increases. The top of the pavement begins to warm up first as the air temperature increases. The temperature variation of the pavement slows with depth, and an obvious low-temperature interlayer appears in the pavement structure, as shown in Fig. 6. Hence, the upper temperature-depth curve of the pavement center in April exhibits a significant left shift. The air temperature continues to rise from April to July. As July is the hottest month with the most solar radiation, the temperature of the pavement center exhibits high-low characteristics as the depth increases. The low-temperature interlayer disappears because the whole pavement is in a high-temperature state. The air temperature gradually decreases from July to October. The temperature of the pavement center starts to decrease and exhibits lowhigh-low characteristics as the depth increases. The top of the pavement is influenced by the external environment first, and begins to decrease in temperature. The temperature variation of the pavement becomes slower with an increase in depth, and the high-temperature interlayer can be clearly seen in the pavement structure, as shown in Fig. 7. Hence, the upper temperature-depth curve of the pavement center in October has a significant right shift. Because the air temperature continues to decrease from October to January, the cooling depth of the pavement increases and the high-temperature interlayer disappears.

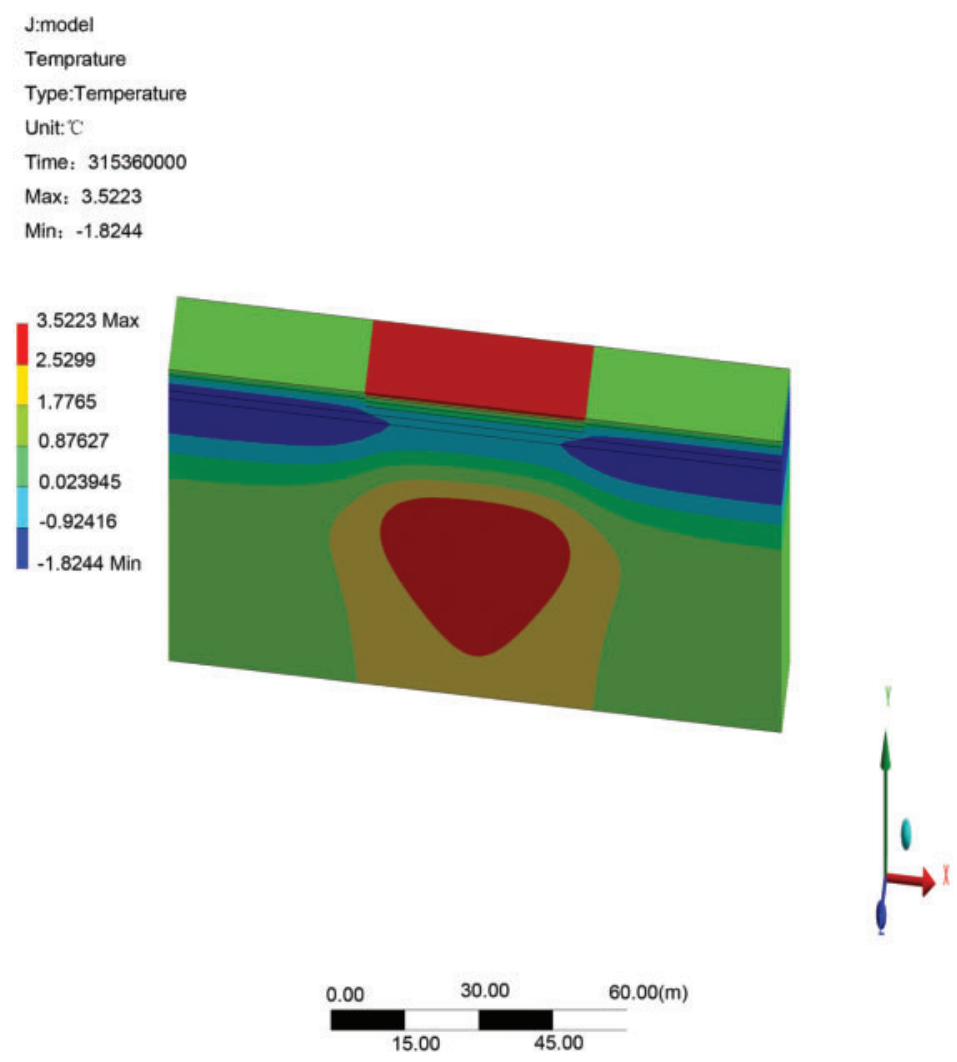

Figure 6: Low-temperature interlayer in the 10th year 


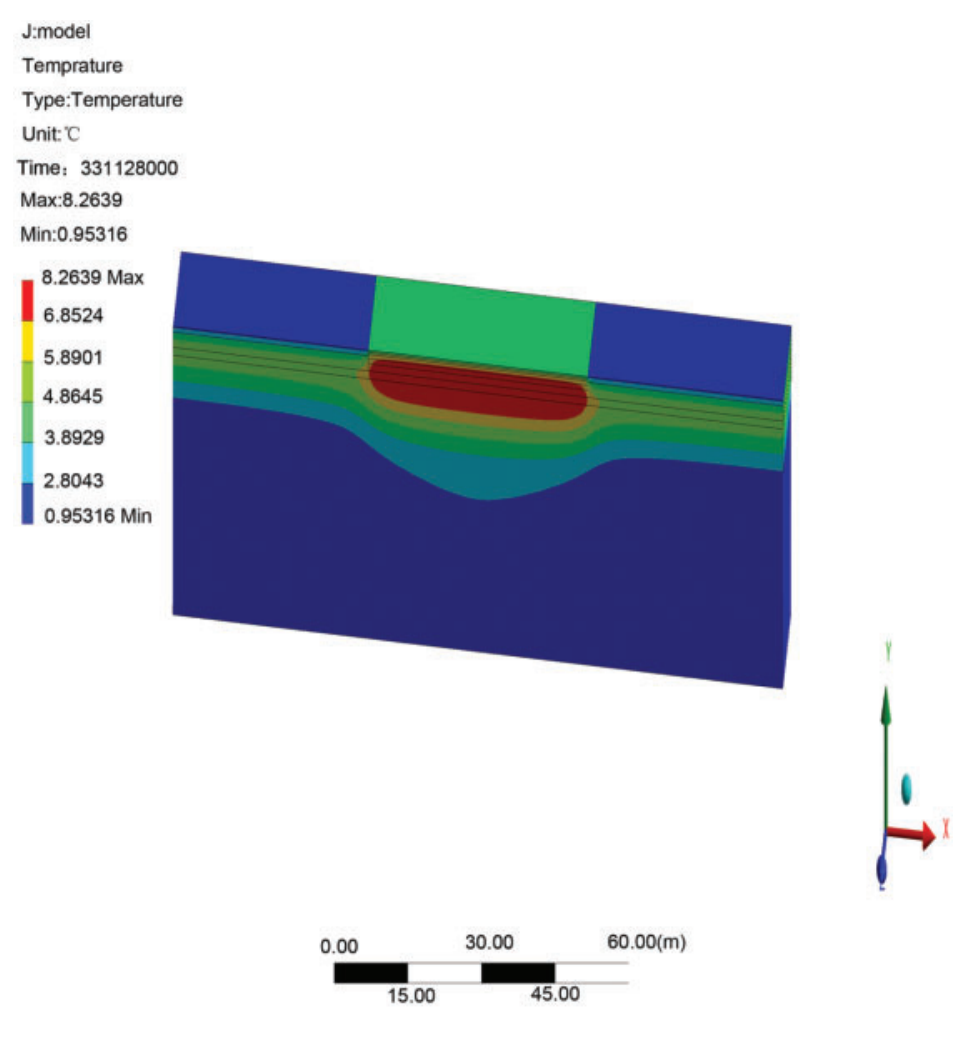

Figure 7: High-temperature interlayer in the 10th year

In Fig. 5b, the characteristics of the temperature-depth curve at different depths and times are similar to those of Fig. 5a. When the air temperature rises from January to April, the clay soil of the natural surface remains frozen for a long time. As the air temperature continues to increase from April to July, the clay soil of the natural surface thaws, but the thermal conductivity of the natural surface is lower than that of the pavement, and so the heat transfer capacity of the natural surface is weaker. The solar absorption coefficient of the natural surface is lower than that of the pavement, meaning that the temperature of the natural surface remains lower than that of the pavement. As the air temperature gradually decreases from July to October, the clay soil of the natural surface remains unfrozen for a long time. Further decreases in the air temperature from October to January gradually cause the clay soil of the natural surface to freeze.

\subsection{Maximum Depth of the Frozen Layer at Different Times}

Because the stability of the temperature field develops year by year, the maximum depth of the frozen layer changes over time. A temperature of $0^{\circ} \mathrm{C}$ is taken as the frozen temperature of the pavement structure layers, natural surface, and subgrade. The maximum depth of the frozen layer curves of the pavement and natural surface over 10 years are shown in Fig. 8.

Fig. 8 shows that the maximum depths of the frozen layer of the pavement and natural surface both decrease year on year due to the impact of global climate warming. The maximum depth of the frozen layer of the pavement is consistently less than that of the natural surface. This is because the solar absorption coefficient and heat transfer capacity of the pavement are greater than those of the natural surface. In runway engineering, the maximum depth of the frozen layer of the pavement is greater than that encountered in highway and railway engineering because the 
wide pavement in runway engineering enables more heat to be absorbed and transferred, enhancing the disturbance range of the permafrost. The variation amplitude of the maximum depth of the frozen layer decreases over time and tends to a stable value as the heat dissipates gradually during the process of transmission. The maximum depth of the frozen layer curves of the pavement center and edge are almost identical, and those of the natural surface center and edge are also very similar. This is because the pavement structure layers, natural surface, and subgrade are assumed to be uniform and isotropic. Hence, the depth of the frozen layer of the pavement center and natural surface center are adopted to study the evolution of the depth of the frozen layer at different times.

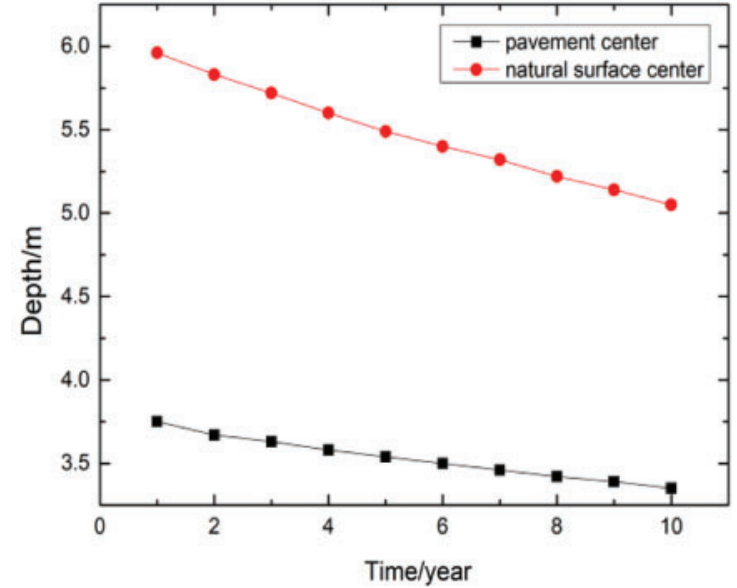

(a)

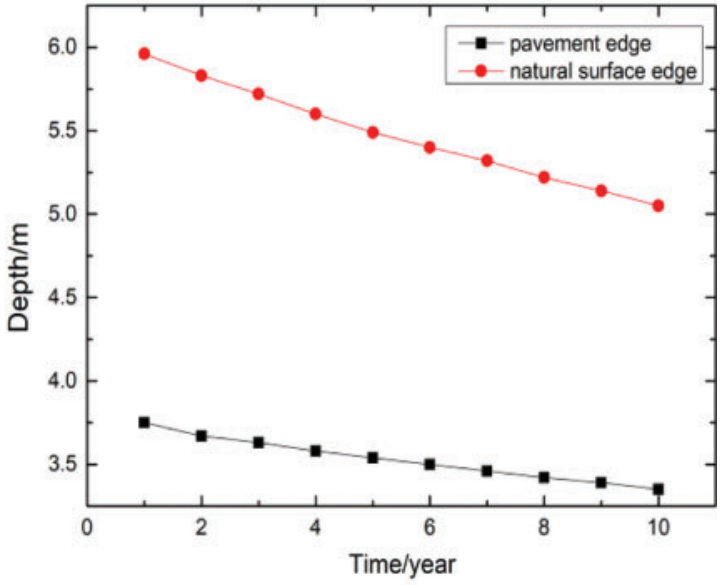

(b)

Figure 8: Maximum depth curve of the frozen layer at (a) pavement center and natural surface center, and (b) pavement edge and natural surface edge

\subsection{Evolution of the Depth of the Frozen Layer at Different Times}

When the maximum depth of the frozen layer has reached an almost-constant value, the pavement structures, natural surface, and subgrade in the vicinity of the maximum depth of the frozen layer undergo a periodic freeze-thaw cycle every year. The changes in the depth of the frozen layer with respect to time for the pavement and natural surface are shown in Fig. 9.

Fig. 9 shows that the range of the depth of the frozen layer for the pavement and natural surface decreases over time because of the impact of global climate warming. The freezing processes of the pavement and natural surface develop from top to bottom, and the thawing processes of the pavement and natural surface develop from top to bottom and from bottom to top. Hence, permafrost runways have the characteristics of unidirectional freezing and bidirectional thawing. Moreover, the thawing rate is faster than the freezing rate. This is because the pavement and natural surface begin to warm up with the coming of spring, and the region beyond the range of the depth of the frozen layer remain at a positive temperature. Both the pavement and natural surface begin to freeze from the middle of October, and reach the maximum depth of the frozen layer at the end of March of the second year. This is because of the thermal resistance effect and thermal transfer delay of pavement structures, natural surface, and subgrade. The start time of thawing is almost identical for the pavement and natural surface, and the time history curves have similar shapes. The freezing and thawing trends for the pavement and natural surface are approximately linear. 


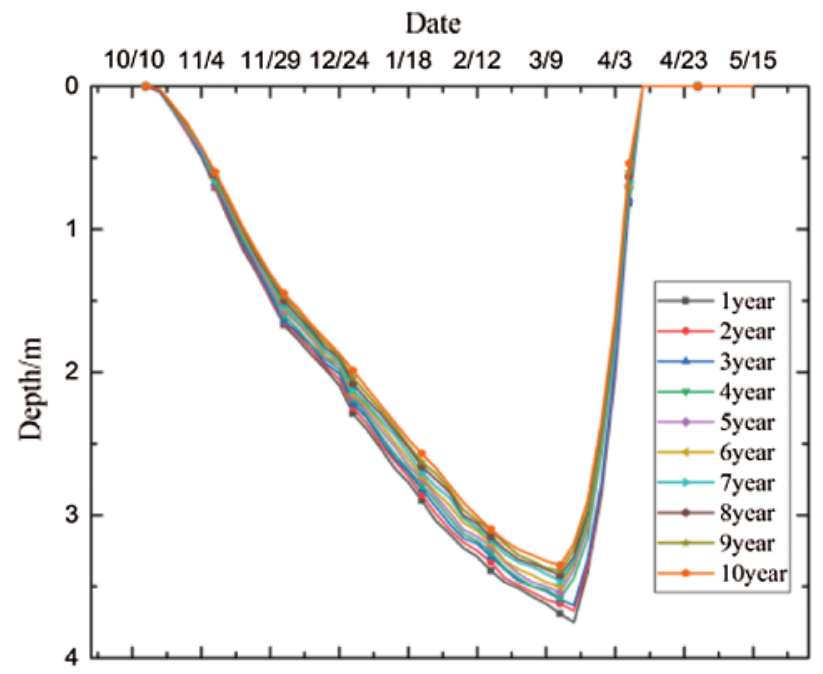

(a)

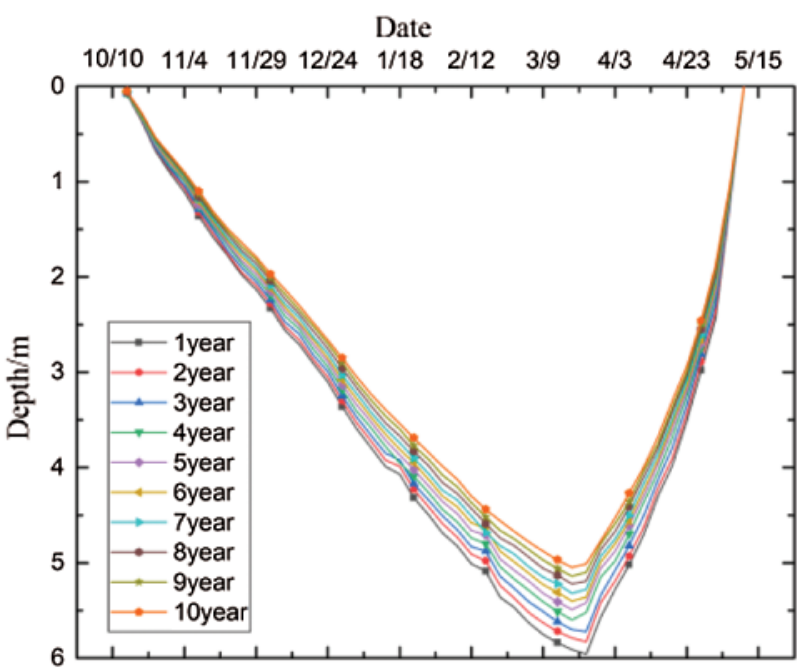

(b)

Figure 9: The depth of the frozen layer with respect to time at (a) pavement center and (b) natural surface center

Although the thawing rates of the pavement and natural surface are similar, the natural surface freezes faster than the pavement, unlike in highway and railway engineering. The depth of the frozen layer the natural surface and the time for which it is frozen are greater than those of the pavement. The reason is that the thawing rates of the pavement and the natural surface are almost identical, but the depth of the frozen layer of the pavement is less than that of the natural surface. Hence, the pavement has completely thawed by the middle of April, whereas the natural surface has not thawed until the middle of May. Note that the low-temperature interlayers remain for a certain time after the pavement and natural surface have thawed.

Because frost deformation occurs in the top-down development of the freezing depth as a result of water from unfrozen areas and outside continuously migrating and accumulating, the frost deformation of the runway should be monitored from November to February every year. The temperature field, ground water level, and rising height of capillary water should also be considered. As thawing occurs faster than freezing and thawing deformation in runway engineering can easily cause significant damage, this issue should be monitored from March to April to ensure the normal operation of the runway and the safe landing and take-off of aircraft.

\section{Structure Optimization}

To verify the cooling effect of the installation layer in airport engineering, the numerical model was used to simulate an installation layer below the subbase layer. Thicknesses of 0.125 , 0.150 , and $0.175 \mathrm{~m}$ were considered. The parameters of the installation layer are listed in Table 3 [39]. The change in temperature with respect to time at the pavement center with an installation layer thickness of $0.150 \mathrm{~m}$ is shown in Fig. 10. The temperature-depth curve at the pavement center for this installation layer thickness is presented in Fig. 11. The maximum depth curve of the frozen layer at the pavement center for all three installation layer thicknesses is shown in Fig. 12. When the depth of the frozen layer reaches its maximum value, the temperature field after 10 years of operation with each installation layer thickness is shown in Fig. 13. The change 
in the depth of the frozen layer with respect to time at the pavement center with an installation layer thickness of $0.150 \mathrm{~m}$ is shown in Fig. 14.

Table 3: Parameters of installation layer

\begin{tabular}{llll}
\hline Material & $\rho /\left(\mathrm{kg} / \mathrm{m}^{3}\right)$ & $c /\left(\mathrm{J} /\left(\mathrm{kg} \cdot{ }^{\circ} \mathrm{C}\right)\right)$ & $\lambda /\left(\mathrm{W} /\left(\mathrm{m} \cdot{ }^{\circ} \mathrm{C}\right)\right)$ \\
\hline XPS & 30 & 1250 & 0.03 \\
\hline
\end{tabular}

Fig. 10 indicates that the temperature changes at the top of the installation layer $(\mathrm{Y}=1.45$ $\mathrm{m})$ and at the bottom of the installation layer $(\mathrm{Y}=1.6 \mathrm{~m})$ have significant differences. The reason is that the installation layer prevents the transmission of heat. Hence, the temperature at the top of the installation layer is similar to the temperature of the pavement structure, whereas the temperature at the bottom of the installation layer is close to the temperature of the subgrade. Moreover, Fig. 10 shows that, at a given time, the maximum (minimum) temperature in the depth range $0.15-1.45 \mathrm{~m}$ is higher (lower) than that indicated in Fig. 4a. This is because the installation layer prevents heat transmission and plays the role of a "pot cover." Therefore, the installation layer is helpful in stabilizing the temperature of the subgrade.

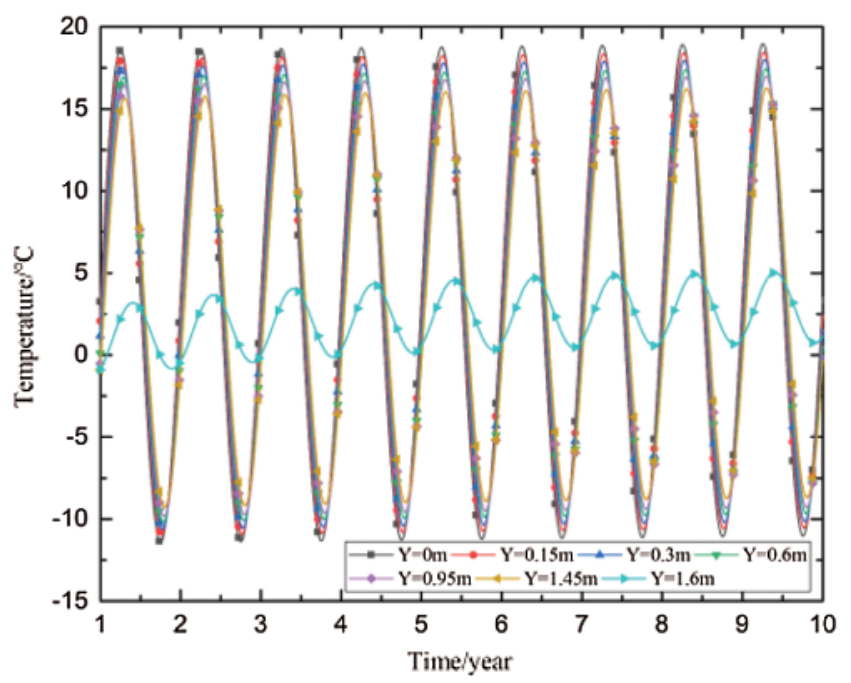

Figure 10: Temperature at pavement center with respect to time for an installation layer thickness of $0.150 \mathrm{~m}$

Fig. 11 shows that the temperature-depth curve changes abruptly at a depth of $1.6 \mathrm{~m}$, and the temperature range from $1.6-12.5 \mathrm{~m}$ is smaller than that shown in Fig. 5a. This phenomenon results from the thermal conductivity of the installation layer being far less than that of the runway structure, preventing the transmission and exchange of heat through the installation layer. Thereby, the installation layer reduces the influence of the air temperature on the temperature field of the subgrade. 


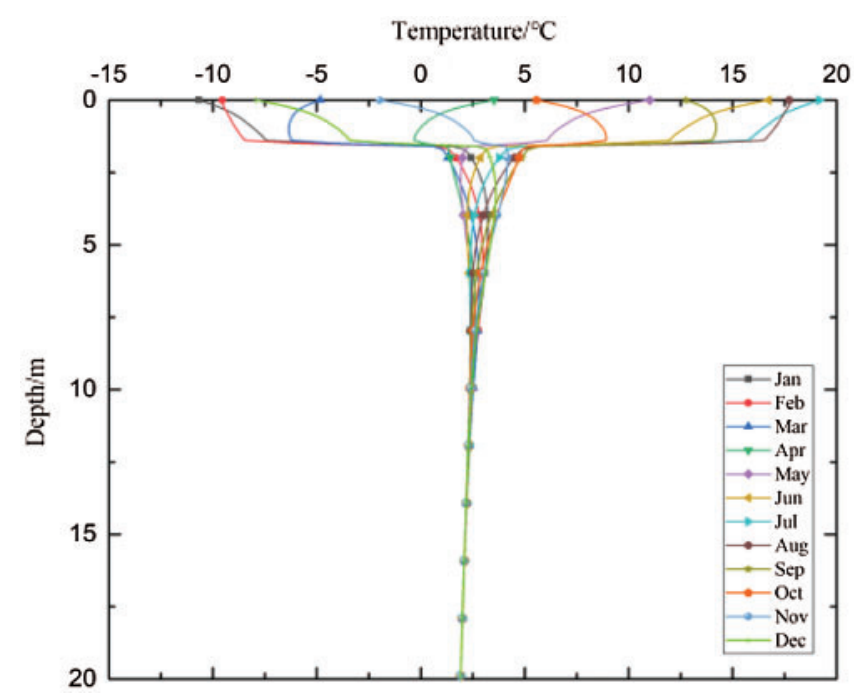

Figure 11: Temperature-depth curve at pavement center with an installation layer thickness of $0.150 \mathrm{~m}$

Fig. 12a indicates that the maximum depth of the frozen layer at the natural surface center is greater than that at the pavement center. The reason is that the natural surface has no installation layer below the subbase layer. The installation layer prevents the transmission and exchange of heat. Fig. $12 \mathrm{~b}$ shows that the maximum depth of the frozen layer decreases over time. The thickness of the installation layer also affects the maximum depth of the frozen layer. Hence, the installation layer is helpful in reducing the maximum depth of the frozen layer.

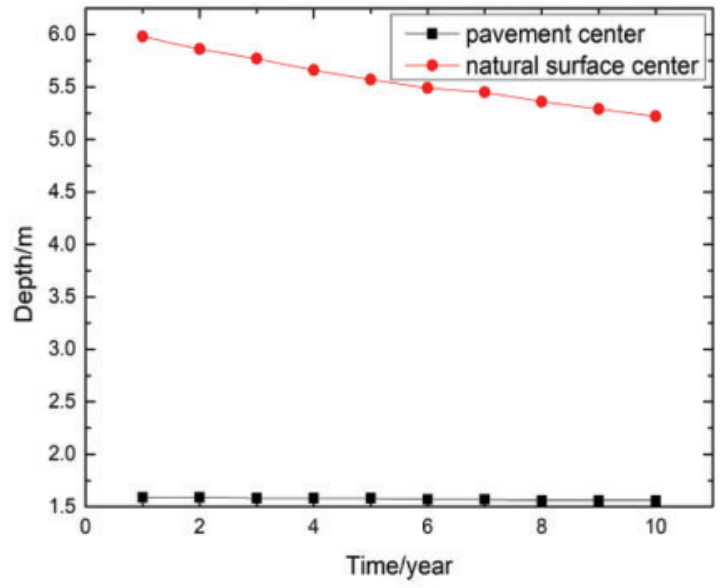

(a)

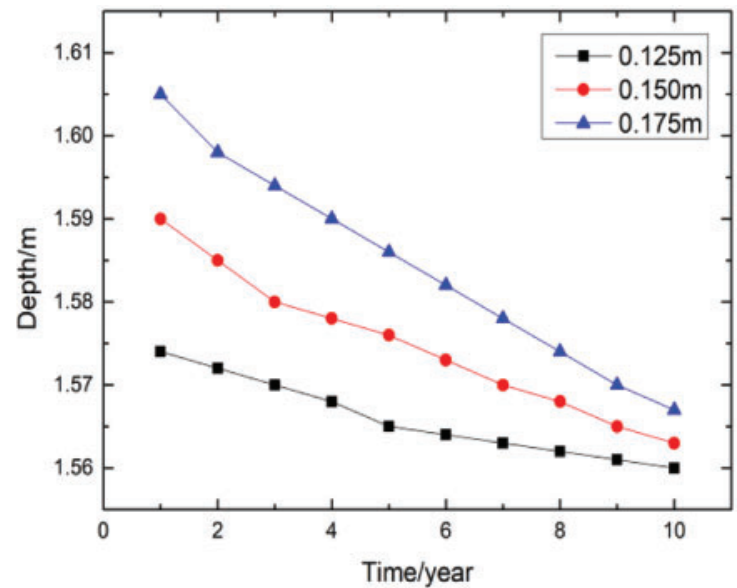

(b)

Figure 12: Maximum depth curve of the frozen layer (a) with an installation layer thickness of $0.150 \mathrm{~m}$ at the pavement center and natural surface center and (b) at the pavement center with installation layer thicknesses of $0.125,0.150$, and $0.175 \mathrm{~m}$ 
Figs. $13 \mathrm{a}$ and $13 \mathrm{~b}$ show that the positive temperature region at the pavement center increases in size and the freezing line at the natural surface gradually moves out as the installation layer thickness increases from 0.125 to $0.150 \mathrm{~m}$. Figs. $13 \mathrm{~b}$ and $13 \mathrm{c}$ show that the positive temperature region at the pavement center decreases in size and the freezing line gradually moves inward when the installation layer thickness increases from 0.150 to $0.175 \mathrm{~m}$. Therefore, the influence of the installation layer on the temperature field weakens away from the pavement toward the natural surface. Moreover, the transverse temperature difference across the pavement structure in Fig. 13 is greater than that shown in Fig. 2.

$$
\begin{aligned}
& \text { E:0.125 } \\
& \text { Temperature } \\
& \text { Type:Temperature } \\
& \text { Unit: 'C } \\
& \text { Time: } 345686400 \\
& \text { Max:2.6343 } \\
& \text { Min:-2.9047 } \\
& \begin{array}{|l}
2.6343 \text { Max } \\
2.0977 \\
1.5611 \\
0.88231 \\
0.25114 \\
-0.38003 \\
-1.0112 \\
-1.6424 \\
-2.2735 \\
-2.9047 \text { Min }
\end{array}
\end{aligned}
$$

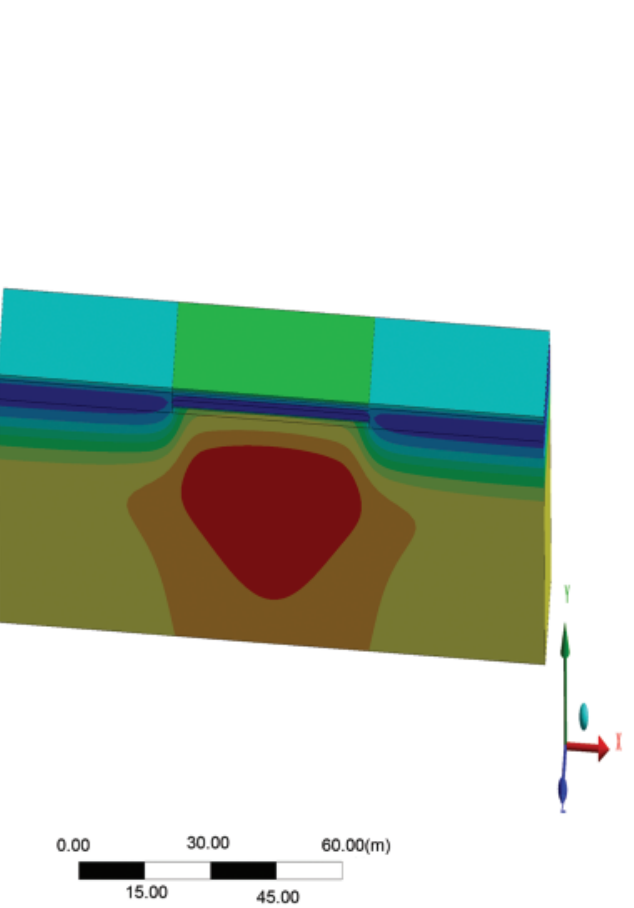

(a)
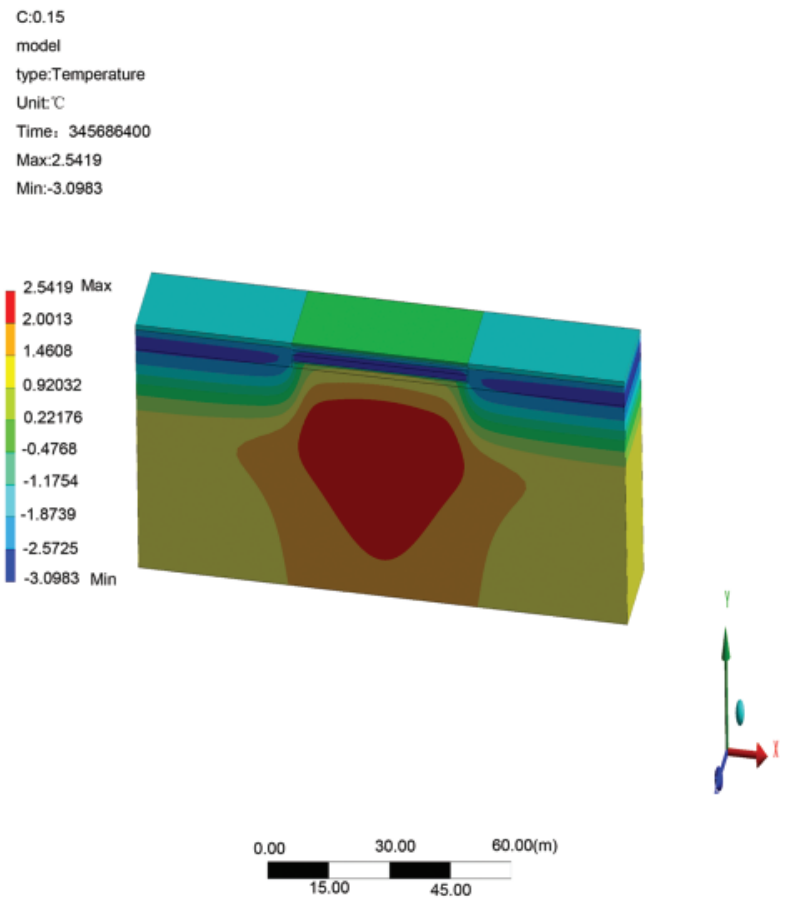

(b)

Figure 13: (continued) 


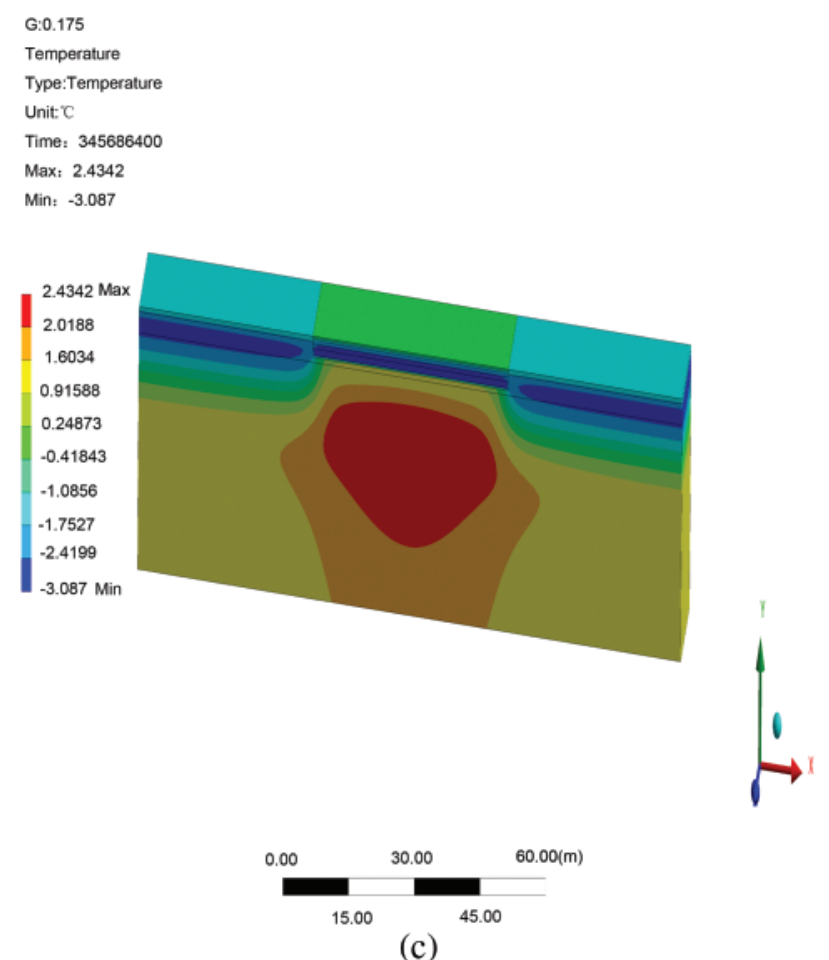

Figure 13: Temperature field after 10 years of operation with installation layer thicknesses of (a) $0.125 \mathrm{~m}$, (b) $0.150 \mathrm{~m}$, and (c) $0.175 \mathrm{~m}$

The freezing rate of the runway in Fig. 14a is slower than that in Fig. 9a, and the freezing rate of the natural surface in Fig. 14b is initially slower than that in Fig. 9b. This is because the installation layer prevents the transmission and exchange of heat, and the effect of installation layer gradually weakens from the pavement to the natural surface. In the process of bidirectional thawing, the influence of the installation layer on temperature transmission reduces the speed of thawing, especially at the natural surface center [Fig. 14b]. Therefore, the installation layer is beneficial to reducing the freezing and thawing rates.

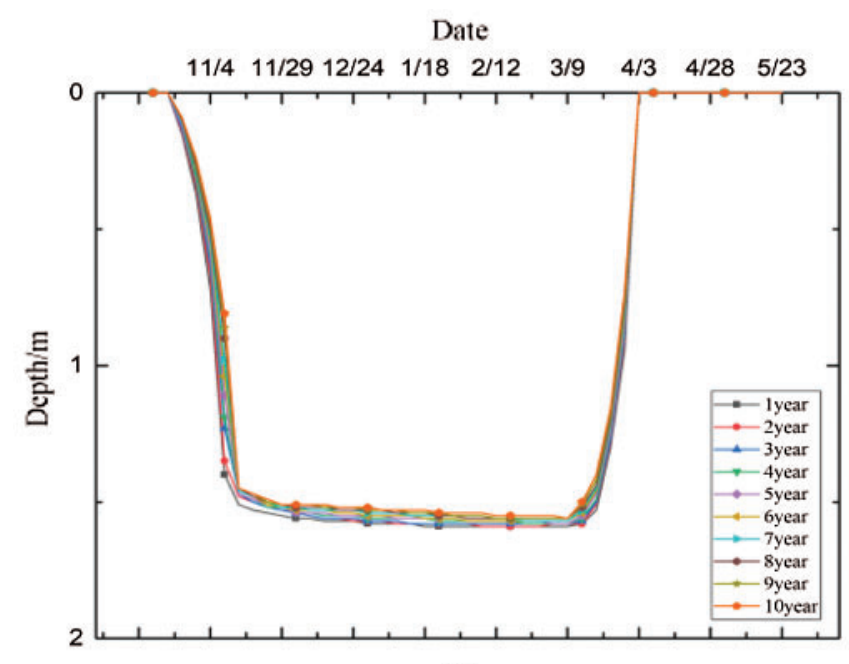

(a)

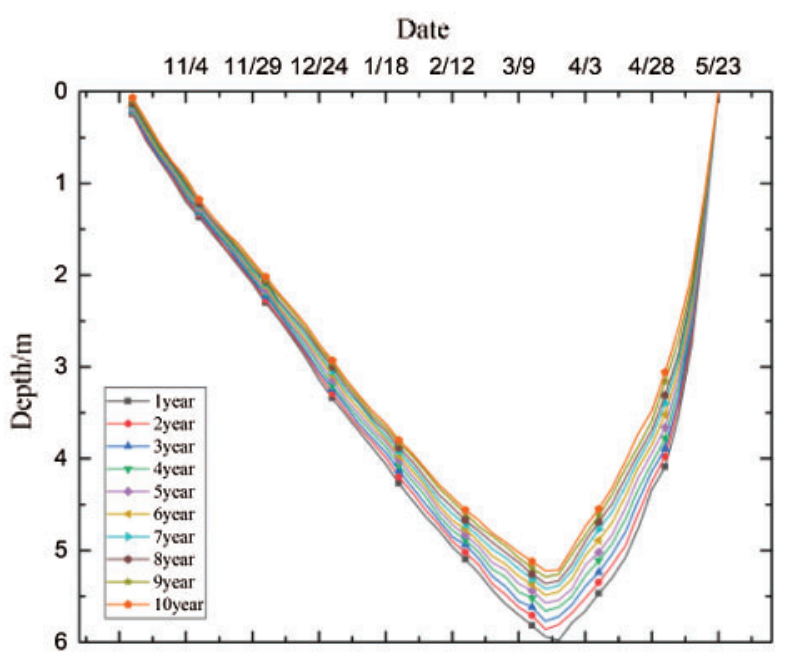

(b)

Figure 14: The depth of the frozen layer with respect to time at (a) pavement center and (b) natural surface center with an installation layer thickness of $0.150 \mathrm{~m}$ 


\section{Conclusions}

Based on the proposed numerical model of runway structures in permafrost regions, the timespace characteristics of the temperature field and the depth of the frozen layer for runways and installation layers have been analyzed. The following conclusions can be drawn:

(1) The heat dissipation processes of the pavement and natural surface continue for 5 or 6 years until the temperature presents a stable and cyclical variation. The temperature amplitudes of the pavement and natural surface gradually decrease, with some phase delay, as the depth increases. The difference in the maximum temperature of the pavement and natural surface is about $3.5^{\circ} \mathrm{C}$, and the difference in the minimum temperature is about $1^{\circ} \mathrm{C}$. The phase delay time of the temperature response in runway engineering is longer than that observed in highway and railway engineering.

(2) The temperature envelopes of the pavement and natural surface are funnel-shaped. The temperature response ranges of the pavement and natural surface decrease as the depth increases and tend to a constant temperature. The depth of temperature stabilization in runway engineering is greater than that in highway and railway engineering. The response range of the low- and high-temperature interlayers in runway engineering is greater than those found in highway and railway engineering.

(3) The maximum depths of the frozen layer of the pavement and natural surface both decrease over time. The variation amplitude of the maximum depth of the frozen layer also decreases with time and tends to a stable value. The maximum depth of the frozen layer of the pavement is less than that of the natural surface at any given time, but is greater than that found in highway and railway engineering.

(4) The range of the depths of the frozen layer for the pavement and natural surface decreases over time. Permafrost runways have the characteristics of unidirectional freezing and bidirectional thawing. The pavement and natural surface exhibit similar freeze/thaw cycles, and the development trends of freezing and thawing for both the pavement and natural surface are approximately linear. The thawing rates of the pavement and natural surface are similar, but the freezing rate of the natural surface is faster than that of the pavement. The natural surface has a greater depth of the frozen layer and a longer frozen period than the pavement.

(5) The change in temperature with time at the top of the installation layer is similar to that of the pavement structure, whereas that at the bottom of the installation layer is similar to that of the subgrade. The temperature-depth curve at the position of the installation layer changes abruptly, and the temperature range from $1.6-12.5 \mathrm{~m}$ is smaller than that of a runway without an installation layer. The maximum depth of the frozen layer decreases over time, and the thickness of the installation layer affects the maximum depth of the frozen layer. The transverse temperature difference across the pavement structure of a runway with an installation layer is greater than that of a runway without an installation layer. The positive temperature region at the pavement center first increases in size and then becomes smaller, and the freezing line at the natural surface first moves away from the runway and then shifts inward. The freezing and thawing rates for a runway with an installation layer are slower than those in a runway without an installation layer.

(6) Due to the time limitation, this paper only studies the temperature of the natural surface and pavement. The next research will be carried out on the stress, strain, and displacement of the natural surface and pavement. The next research will propose empirical equations for the stress, strain, and displacement. 
Funding Statement: The authors gratefully acknowledge the National Natural Science Foundation of China (Grant No. 52108333), the Natural Science Foundation of Tianjin (Grant Nos. 18JCQNJC08300, 18JCYBJC90800, 20JCQNJC01320) and the Key Laboratory of Road Structure and Materials Transportation Industry (Grant No. 310821171114) for providing the funding that made this study possible.

Conflicts of Interest: The authors declare that they have no conflicts of interest to report regarding the present study.

\section{References}

1. Chou, Y. L., Sheng, Y., Chen, J., Chen, X. Q. (2015). Analysis on thermal stability and deformation stability of CMR. Cold Regions Science and Technology, 110(6), 215-222. DOI 10.1016/j.coldregions.2014.10.004.

2. Mu, Y. H., Ma, W., Niu, F. J., Liu, Y. Z., Fortier, R. et al. (2018). Long-term thermal effects of air convection embankments in permafrost zones: Case study of the Qinghai-Tibet railway. China Cold Regions Science and Technology, 32(4), 1-9. DOI 10.1061/(ASCE)CR.1943-5495.0000166.

3. Kong, X. B., Dore, G., Calmels, F. (2019). Thermal modeling of heat balance through embankments in permafrost regions. Cold Regions Science and Technology, 158(4), 117-127. DOI 10.1016/j.coldregions.2018. 11.013.

4. Ming, F., Yu, Q. H., Li, D. Q. (2018). Investigation of embankment deformation mechanisms in permafrost regions. Transportation Geotechnics, 16(6), 21-28. DOI 10.1016/j.trgeo.2018.06.003.

5. Liu, Z. Q., Yang, W. H., Wei, J. (2014). Analysis of random temperature field for freeway with wide subgrade in cold regions. Cold Regions Science and Technology, 106(8), 22-27. DOI 10.1016/j.coldregions.2014.06.004.

6. Zhang, Z., Yu, Q., You, Y., Lei, G., Wang, X. B. et al. (2020). Cooling effect analysis of temperaturecontrolled ventilated embankment in Qinghai-Tibet testing expressway. Cold Regions Science and Technology, 173(6), 10-32. DOI 10.1016/j.coldregions.2020.103012.

7. Harlan, R. L. (1973). Analysis of coupled heat fluid transport in partially frozen soil. Water Resources Research, 9(5), 1314-1323. DOI 10.1029/WR009i005p01314.

8. Dempsey, B. J. (1978). A mathematical model for predicting coupled heat and water movement in unsaturated soil. International Journal for Numerical \& Analytical Methods in Geomechanics, 2(1), 19-34. DOI 10.1002/(ISSN)1096-9853.

9. Noorishad, J., Tsang, C. F., Witherspoon, P. A. (1984). Coupled thermal-hydraulic-mechanical phenomena in saturated fractured porous rocks: Numerical approach. Journal of Geophysical Research, 89( B12), 10365 10373. DOI 10.1029/JB089iB12p10365.

10. Mu, S., Ladanyi, B. (1987). Modelling of coupled heat, moisture and stress field in freezing soil. Cold Regions Science and Technology, 14(3), 237-246. DOI 10.1016/0165-232X(87)90016-4.

11. Masters, I., Pao, W. K. S., Lewis, R. W. (2000). Coupling temperature to a double-porosity model of deformable porous media. International Journal for Numerical Methods in Engineering, 49(3), 421-438. DOI 10.1002/(ISSN)1097-0207.

12. Fortier, R., Leblanc, A. M., Yu, W. (2011). Impacts of permafrost degradation on a road embankment at Umiujaq in Nimavik (Quebec). Canada Revue Canadienne de Géotechnique, 48(5), 720-740. DOI 10.1139/t10-101.

13. Sergei, K., Tatiana, V., Alexei, K., Elena, G., Lurii, B. (2013). Predictive modeling of the permafrost thermal regime in Russian railroad subgrade support systems. Sciences in Cold and Arid Regions, 5(4), 404-407. DOI 10.3724/SP.J.1226.2013.00404.

14. Chen, L., Yu, W. B., Yang, C. S., Yi, X., Liu, W. B. (2014). Conductivity of aeolian sand on the Tibet Plateau based on microstructure. Journal of Glaciology and Geocryology, 36(5), 1220-1226. DOI 10.7522/j.issn.1000-0240.2014.0146.

15. Chen, L., Yu, W., Lu, Y., Liu, W. B. (2017). Numerical simulation on the performance of thermosyphon adopted to mitigate thaw settlement of embankment in Sandy permafrost zone. 
Applied Thermal Engineering Design Processes Equipment Economics, 128(5), 1624-1633. DOI 10.1016/j.applthermaleng.2017.09.130.

16. Chen, L., Yu, W. B., Yi, X., Hu, D., Liu, W. B. (2018). Numerical simulation of heat transfer of the crushedrock layer embankment of Qinghai-Tibet Railway affected by aeolian sand clogging and climate change. Cold Regions Science and Technology, 155(2), 1-10. DOI 10.1016/j.coldregions.2018.07.009.

17. Liu, Z. Y., Cui, F. Q., Chen, J. B., Jin, L., Wang, W. et al. (2020). Study on the permafrost heat transfer mechanism and reasonable interval of separate embankment for the Qinghai-Tibet expressway. Cold Regions Science and Technology, 170(1), 1-9. DOI 10.1016/j.coldregions.2019.102952.

18. He, P., Zhang, Z., Cheng, G. D., Hui, B. (2007). Ventilation properties of blocky stones embankments. Cold Regions Science and Technology, 47(5), 271-275. DOI 10.1016/j.coldregions.2006.07.002.

19. Bian, X. L., He, P., Wu, Q. B., Shi, Y. H. (2010). Laboratory experiment of natural convection characteristics of embankment block stones. Journal of the China Railway Society, 32(5), 77-81. DOI 10.3969/j.issn.1001-8360.2010.05.014.

20. Li, Y. (2019). Study on runway subgrade moisture-heat-stress coupling effect in permafrost regions (Master Thesis). Civil Aviation University of China, Tianjin.

21. Yu, Q. H., Fan, K., You, Y. H., Guo, L., Cheng, Y. (2015). Comparative analysis of temperature variation characteristics of permafrost roadbeds with different widths. Cold Regions Science and Technology, 117(3), 12-18. DOI 10.1016/j.coldregions.2015.05.002.

22. Yu, Q. H., Mu, Y. H., Yuan, C., Wei, M., Pan, X. C. (2019). The cold accumulative effect of expressway embankment with a combined cooling measure in permafrost zones. Cold Regions Science and Technology, 163(5), 59-67. DOI 10.1016/j.coldregions.2019.04.009.

23. Harris, S. A., Pedersen, D. E. (1998). Thermal regimes beneath coarse blocky materials. Permafrost and Periglacial Processes, 9(5), 107-120. DOI 10.1002/(ISSN)1099-1530.

24. Qin, Y. H., Zhang, J. M. (2010). Estimating the stability of unprotected embankment in warm and icerich permafrost region. Cold Regions Science and Technology, 61(1), 65-71. DOI 10.1016/j.coldregions. 2009.12.001.

25. Qian, J., Yu, Q. H., You, Y. H., Hu, J., Guo, L. (2012). Analysis on the convection cooling process of crushedrock layer embankment of high-grade highway in permafrost regions. Cold Regions Science and Technology, 78(4), 115-121. DOI 10.1016/j.coldregions.2012.01.010.

26. Doré, G., Niu, F., Brooks, H. (2016). Adaptation methods for transportation infrastructure built on degrading permafrost. Permafrost and Periglacial Processes, 56(1), 352-364. DOI 10.1002/ppp.1919.

27. Varlamov, S. P. (2018). Thermal monitoring of railway subgrade in a region of ice-rich permafrost, Yakutia, Russia. Cold Regions Science and Technology, 155(2), 184-192. DOI 10.1016/j.coldregions.2018.06.016.

28. Liu, J. K., Tai, B. W., Fang, J. H. (2019). Ground temperature and deformation analysis for an expressway embankment in warm permafrost regions of the Tibet plateau. Permafrost and Periglacial Processes, 30(3), 208-221. DOI 10.1002/ppp.2007.

29. Niu, F. J., Cheng, G. D., Xia, H. M., Ma, L. F. (2006). Field experiment study on effects of duct-ventilated railway embankment on protecting the underlying permafrost. Cold Regions Science and Technology, 45 (3), 178-192. DOI 10.1016/j.coldregions.2006.03.004.

30. Cheng, G. D., Wu, Q. B., Ma, W. (2009). Innovative designs of permafrost roadbed for the Qinghai-Tibet Railway. Science China Technological Sciences, 52(2), 530-538. DOI 10.1007/s11431-008-0291-6.

31. Tai, B. W., Liu, J. K., Wang, T. F., Tian, Y. H., Fang, J. H. (2017). Thermal characteristics and declining permafrost table beneath three cooling embankments in warm permafrost regions. Applied Thermal Engineering, 123(6), 435-447. DOI 10.1016/j.applthermaleng.2017.05.031.

32. Tai, B. W., Liu, J. K., Yue, Z. R., Liu, J. Y., Tian, Y. H. et al. (2018). Effect of sunny-shady slopes and strike on thermal regime of subgrade along a high-speed railway in cold regions. China Engineering Geology, 232(4), 182-191. DOI 10.1016/j.enggeo.2017.09.002.

33. Tai, B. W., Zhou, G. Q., Wang, J. Z., Zhou, Y., Chen, T. (2019). Stochastic coupling analysis of uncertain hydro-thermal properties for embankment in cold regions. Transportation Geotechnics, 21, 100275. DOI 10.1016/j.trgeo.2019.100275. 
34. Esch, D. C. (1988). Insulation performance beneath roads and airfields in Alaska. Cold Regions Engineering, 5(1146), 713-722.

35. Jin, H. J., Brewer, M. C. (2005). Experiences and lessons learned in the engineering design and construction in the Alaska Arctic. Journal of Glaciology \& Geocryology, 27(1), 140-145. DOI 10.1360/gs050303.

36. Liu, W. B. (2015). Techniques of airport runway construction in permafrost regions: A review. Journal of Glaciology \& Geocryology, 37(6), 1599-1610. DOI 10.7522/j.issn.1000-0240.2015.0177.

37. Civil Aviation Administration of China (2017). Specifications for asphalt pavement design of civil airports. Beijing: China Civil Aviation Publishing House.

38. Duan, S. H. (2019). The study of the application of gravel-filled layer in the construction of runway in permafrost regions (Master Thesis). Civil Aviation University of China, Tianjin.

39. Wang, X. T. (2019). Optimization study for subgrade structure of high-speed railway in deep seasonally frozen region based on temperature field (Master Thesis). Beijing Jiaotong University, Beijing.

40. Wang, T., Zhou, G. Q., Wang, J. Z., Zhou, Y., Chen, T. (2019). Stochastic coupling analysis of uncertain hydro-thermal properties for embankment in cold regions. Transportation Geotechnics, 21(2), 1-10. DOI 10.1016/j.trgeo.2019.100275. 